\title{
Breathing mode influence in craniofacial development
}

\section{Fernanda Campos Rosetti Lessa ${ }^{1}$, Carla Enoki, Murilo Fernandes Neuppmann Feres ${ }^{3}$, Fabiana Cardoso Pereira Valera 4 , Wilma Terezinba Anselmo Lima ${ }^{5}$, Mirian Aiko Nakane Matsumoto ${ }^{6}$}

Key words: craniofacial development, mouth breathers, facial height.

\section{Summary}

\begin{abstract}
A im: the aim of this study was to evaluate the differences in facial proportions of nose and mouth breathing children using cephalometric analysis. Study design: transversal cohort. Material and Method: Sixty cephalometric radiographs from pediatric patients aged 6 to 10 years were used. After otorhinolaryngological evaluation, patients were divided into two groups: Group I, with mouth breathing children and group II, with nose breathers. Standard lateral cephalometric radiographs were obtained to evaluate facial proportions using the following measures: SN.GoGn, ArGo.GoMe, N-Me, N-ANS, ANS-Me and S-Go; and the following indexes: PFH-AFH ratio: S-Go/N-Me; LFH-AFH ratio: ANS-Me/N-Me and UFH-LFH ratio: N-ANS/ANS-Me. Results: It was observed that the measurements for the inclination of the mandibular plane (SN.GoGn) in mouth breathing children were statistically higher than those in nasal breathing children. The posterior facial height was statistically smaller than the anterior one in mouth breathing children (PFH-AFH ratio). Thus, the upper anterior facial height was statistically smaller than the lower facial height (UFH-LFH ratio). Conclusion: We concluded that mouth breathing children tend to have higher mandibular inclination and more vertical growth. These findings support the influence of the breathing mode in craniofacial development.
\end{abstract}

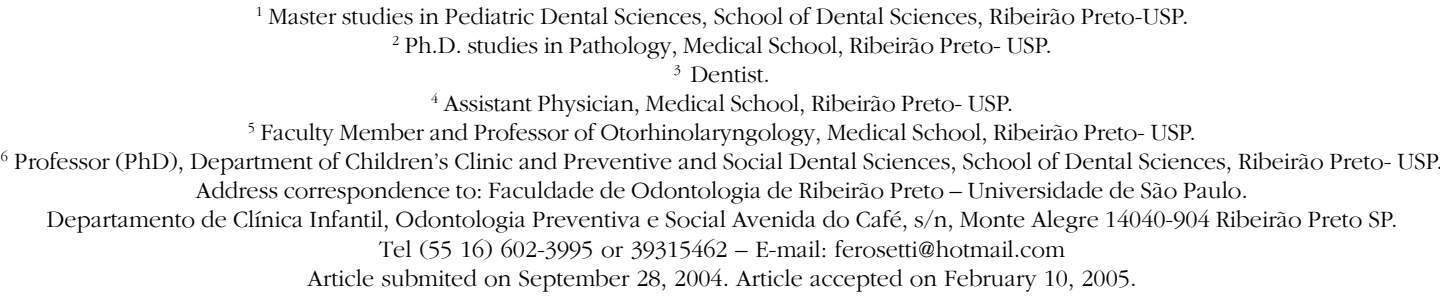

Brazilian Journal of Otorhinolaryngology 71 (2) Part 1 March/April 2005

http://www.rborl.org.br / e-mail: revista@aborlccf.org.br 


\section{INTRODUCTION}

The influence of respiratory function in development of orofacial structures has been widely discussed. According to Moss's Theory of Functional Matrix (Moss $\left.{ }^{1}, 1969\right)$, nasal breathing allows proper growth and development of the craniofacial complex interacting with other functions such as mastication and swallowing (Prates ${ }^{2}$ et al., 1997). This theory is based on the principle that facial growth is closely related to functional activity represented by different components of the head and neck region.

Nasal obstruction, however, leads to mouth breathing resulting in change of the tongue's position and half opened lips (Linder-Aronson 3 , 1970; Principato ${ }^{4}, 1991$; Proffit 5 , 1993). Therefore, any occlusion in the upper airways whether due to malformation, nasal mucosa inflammatory reaction (rhinitis), nasal septum deviation or Waldeyer's ring hypertrophy will result in nasal obstruction forcing the patient to breath through the mouth (Weckx \& Weckx 6 , 1995). If we consider the doctrine of functional matrixes, the obstruction of nasal and ororespiratory airways may have impact on growth orientation of facial skeleton structure (Subtelny ${ }^{7}, 1975$ ).

The child with chronic mouth breathing, whether due to nasal obstruction or not, develops several morphological disorders during growth phase resulting in unfavorable dental-facial complex development (Linder-Aronson ${ }^{3}$, 1970; Shendal ${ }^{8}$ et al., 1976; Hulcrants9 et al., 1991).

Although there is significant evidence that poor nasal breathing will lead to mouth-nasal breathing its impact in dental facial growth is still unclear (Warren ${ }^{10}, 1990$ ).

Other authors disagreed from the statement that facial morphology and breathing mode are closely related (Warren $^{10}$, 1990; Tourné ${ }^{11}$, 1991; Tourné \& Scheweiger ${ }^{12}$, 1996).

These facts show clear need for further investigation about the impact of mouth breathing on dental facial growth and development at an early age. Therefore, this study will evaluate the morphological pattern of the face through side cephalometric radiographs in order to report existing differences between nasal and mouth breathing pediatric patients.

\section{OBJECTIVE}

The objective of this study was to evaluate through cephalometric analysis the differences in facial proportion between mouth breathing children and normal breathing pediatric patients.

\section{MATERIAL AND METHOD}

First this study was submitted and approved by the Ethics Committee of the Dental School, Ribeirão Preto- USP under \# 2003.1.372.58.1. Sixty pediatric patients aged 6 to 10 years underwent otorhinolaryngological evaluation to diagnose the type of breathing mode in the outpatient center of Otorhinolaryngology of the Clinical Hospital, Medical School, Ribeirão Preto- USP, with history of patients and otorhinolaryngological examination (oroscopy - Brodsky \& Kock $^{13}$, 1992; anterior rhinoscopy; otoscopy and lateral skull radiograph - Cohen \& $\operatorname{Konak}^{14}$, 1985) and data were recorded in a previously designed protocol.

Pediatric patients were divided into two groups: Group I with mouth breathing children with severe airways obstruction used as experimental group, and Group II with nasal breathing children as control group. The two selected populations did not have previous history of nasal respiratory complex surgery or orthodontic treatment.

After selecting the two groups with nose and mouth breathing children patients underwent orthodontic evaluation through lateral cephalometric radiography. During radiographic procedure lead apron was used to protect patients. The same technician using the same device performed the exam under standardized technique.

Contour tracings were performed for dental facial anatomic structures and soft tissues of concern for the purposes of this study.

Cephalometric points marked in cephalograms were as follows: (Figure 1)

- (S) Sella : Mid point of sella turcica;

- (N) Nasion: Most anterior point on fronto-nasal suture;

- (A) point: Position of deepest concavity on anterior profile of maxilla;

- (Go) Gonion: Most posterior inferior point on angle of mandible;

- (Me) Menton: Point located in the intersection between cortical external mental portion and cortical inferior mandible portion. Lowest point on the mandibular symphysis.

- (ANS) Anterior Nasal Spine - point located at the end of the anterior nasal spine;

- (Gn) Gnathion - most anterior and lowest point on the mandibular symphysis determined by bisectrix of the angle formed between the mandibular plane and a perpendicular line of it tangentially to the most anterior region of the symphysis;

- (Ar )Articulare - point located at the cross-section of posterior contour of the mandibular condyle with the occipital bone base.

After locating the landmarks of anatomical skeletal points, cephalometric angular and linear measurements obtained were as follows:

1) SN.GoGn Angle: determined by the intersection of S-N line with the mandibular plane (Go-Gn). Gives the 


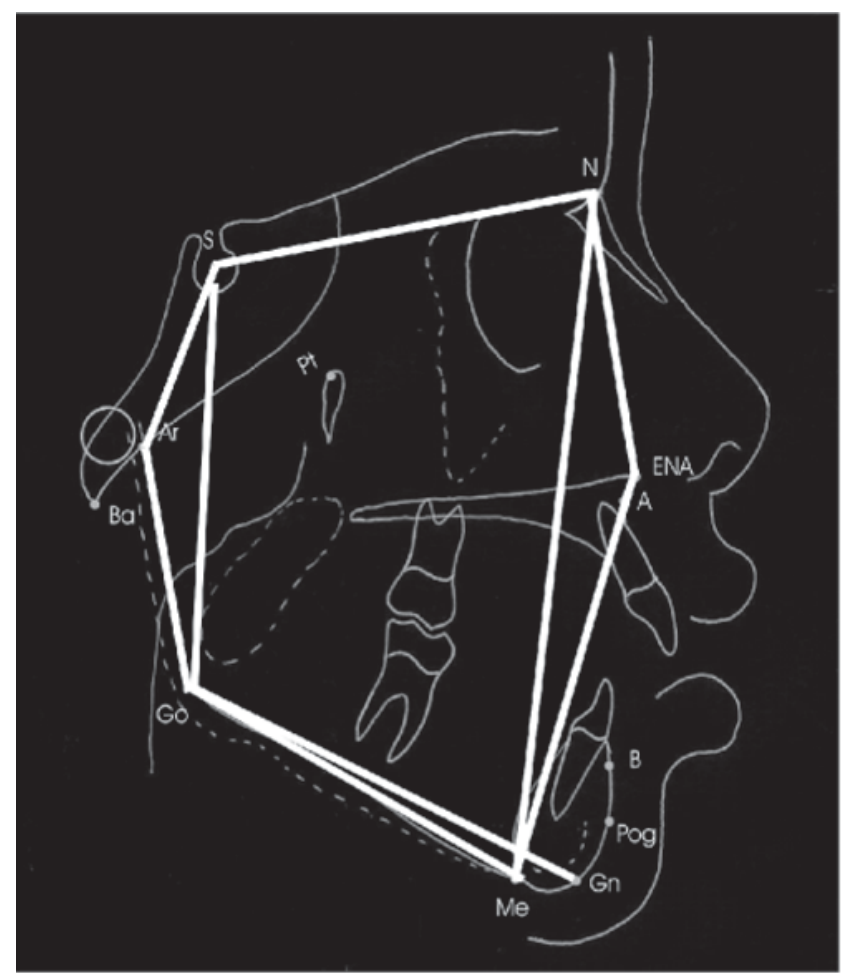

Figure 1. Angles and measures traced in this study.

inclination of the mandibular plane relative to anterior base of the skull.

2) ArGo.GoMe Angle (Gnathion Angle): determined by the junction of the ArGo line with GoMe line. Gives the degree inclination of the ramus relative to the mandible body.

3) N-Me Angle: linear measurement corresponding to the facial height of the anterior face.

4) N-ANS Angle: Represents the anterior upper height of the face.

5) ANS-Me Angle: Establishes the anterior lower height of the face.

6) S-Go Angle: Linear measure that gives the posterior height of the face.

7) S-Ar Angle: Gives the upper posterior height of the face.

8) Ar-Go Angle: Gives the lower posterior height of the face.

After performing cephalometric measurements the proposed indexes were as follows:

1- (iAF) Facial Height Index, obtained from the posterior facial height and total anterior facial height ratio. $(\mathrm{iAF}=$ $\mathrm{S}-\mathrm{Go} / \mathrm{N}-\mathrm{Me}$ ).

2- (iAFA) Index of Facial Height, obtained from the anterior lower facial height and total anterior facial height ratio. $(\mathrm{iAFA}=$ ANS-Me $/ \mathrm{N}-\mathrm{Me})$.

3- Index of Anterior Facial Ratio (iPFA), obtained from anterior upper facial height and lower anterior facial height ratio. $(\mathrm{iPFA}=\mathrm{N}-\mathrm{ANS} /$ ANS-Me).

\section{RESULTS}

Two groups were formed with 30 male and female patients each (Table 2), aged from 6 to 10 years as shown in Table 1.

Table 3 shows data related to mean values, standard deviation and p-value obtained from T Student test to compare the means of patients with nasal and mouth breathing. Statistically significant differences found $(\mathrm{p}<0.05)$ between both groups in SN.GoGn, iAF and iPFA, that is, the values of mandibular plane inclination in mouth breathing children were statistically higher than those of nasal breathing children. Posterior and anterior facial height ratio and anterior upper and lower facial height ratio were statistically lower in mouth breathing children against the nasal-breathing children.

\section{DISCUSSION}

Inadequate growth of dentofacial complex results from several genetic and environmental factors. The presence of mouth breathing in pediatric patients is a relatively common fact and may result in a series of changes of facial skeleton as well as in malocclusions (Aragão ${ }^{15}$, 1985).

The impact of nasal obstruction in facial and dental growth is quite controversial due to the criterion used to define mouth breathing, which is many times a subjective one. The lack of straightforwardness of these exams may result in incorrect diagnostics and consequently in inadequate treatment. In this study, the diagnosis of the type of breathing was made by oroscopy (Brodsky \& Kock ${ }^{13}$, 1992), anterior rhinoscopy, otoscopy and lateral skull radiography (Cohen \& $\operatorname{Konak}^{14}$, 1985). Thus, such otorhinolaryngological evaluation ensured correct diagnosis.

Some studies report that mouth-nose breathing is not necessarily deleterious to growth (Hinton ${ }^{16}$, 1986). If nasopharyngeal and oropharyngeal air space are reduced, patients with mouth-nose breathing mode have excessive postural responses which contribute to increased antero-lower facial development increasing mandibular plane inclination that may impact dentofacial development (Warren ${ }^{10}$, 1990; Tourne $\left.{ }^{12}, 1996\right)$. Craniofacial morphology and dental patterns are affected by mouth breathing sustained for long periods during high potential growth spurs (Principato ${ }^{4}$, 1991; Lyle $^{17}$, 2000).

This study evidenced that mandibular plane inclination in mouth breathing children was higher than that of nasal breathing children. Kawashima ${ }^{18}$ et al. (2002) and Kerr ${ }^{19}$ et al. (1989) reported the same findings in younger children in pre-school age (3 to 6 years): mandible may be retrognathic and posteriorly inclined, particularly if the level of respiratory obstruction ranges from moderate to severe. This condition could determine the increase in anterior facial height due to clockwise mandibular displacement, showing a vertical growth pattern in older children (11 to 14 years) as reported by Yang ${ }^{20}$ at al. (2002). 
Table 1. Age frequency of patients in each group

\begin{tabular}{cccccc}
\hline Age(years) & \multicolumn{2}{c}{ Type of breathing } & Total \\
& \multicolumn{2}{c}{ Nasal } & \multicolumn{2}{c}{ Mouth } & \\
& $\mathrm{n}^{\circ}$ & $\%$ & $\mathrm{n}^{\circ}$ & $\%$ & \\
\hline $6-7$ & 4 & 13.3 & 7 & 23.3 & 11 \\
$7-8$ & 13 & 43.3 & 12 & 40.0 & 25 \\
$8-9$ & 8 & 26.6 & 8 & 26.6 & 16 \\
$9-10$ & 5 & 16.6 & 3 & 10.0 & 8 \\
\hline Total & 30 & 100.0 & 30 & 100.0 & 60 \\
\hline
\end{tabular}

Table 2. Gender distribution frequency of children in each group

\begin{tabular}{cccccc}
\hline Gender & \multicolumn{4}{c}{ Type of breathing } & Total \\
& \multicolumn{2}{c}{ Nasal } & \multicolumn{2}{c}{ Mouth } & \\
& $\mathrm{n}^{\circ}$ & $\%$ & $\mathrm{n}^{\circ}$ & $\%$ & \\
\hline $\mathrm{F}$ & 16 & 53.3 & 23 & 76.6 & 39 \\
$\mathrm{M}$ & 14 & 46.6 & 7 & 23.3 & 21 \\
\hline Total & 30 & 100.0 & 30 & 100.0 & 60 \\
\hline
\end{tabular}

Table 3. Mean values, Standard Deviations and $p$-value of Student's $T$ test in the nasal and mouth breathing children comparison.

\begin{tabular}{|c|c|c|c|c|c|}
\hline & \multicolumn{2}{|c|}{ Nasal Breathing } & \multicolumn{2}{|c|}{ Mouth } & \multirow[t]{2}{*}{$\mathrm{p}$-valUE } \\
\hline & Mean & SD & Mean & SD & \\
\hline SN.GoGn & 33.16 & 4.09 & 36.36 & 5.22 & $0.011^{*}$ \\
\hline ArGo.GoMe & 131.73 & 4.62 & 134.03 & 5.72 & 0.092 \\
\hline $\mathrm{IAF}$ & 0.62 & & 0.60 & & $0.014^{*}$ \\
\hline IAFA & 0.57 & & 0.58 & & 0.084 \\
\hline IPFA & 0.77 & & 0.73 & & $0.045^{\star}$ \\
\hline
\end{tabular}

Level of significance $5 \%(p<0.05)$

The facial height index could be used to diagnose excessive or deficient vertical dimension, as an indicator of mandibular rotation during treatment. If anterior facial height is increased relatively to posterior facial height, there are some signs that the mandible rotates downwards and backwards $\left(\operatorname{Horn}^{21}, 1992\right)$. In this study posterior and anterior facial height ratio (iAF) and anterior upper and lower facial height ratio (iPFA) were statistically lower in mouth breathing children, indicating proportionally lower posterior facial height than anterior facial height, and anterior lower facial height higher than upper facial height in these patients. This fact confirms the evidence that mouth breathing children present clockwise rotation of the mandible stimulating increased vertical growth of the anterior portion of the face relatively to the posterior portion of the face. Tourné $^{22}$ (1990) highlighted the hypothesis that mouth breathing should be considered as the major etiological factor of induced excessive vertical growth. Ung ${ }^{23}$ et al. (1990) reported that mouth breathing, regardless of being analyzed through subjective perception, was associated with increased anterior facial height. Conversely, Smith \& Gonzalez $^{24}$ (1989) \& Warren ${ }^{10}$ (1990) stated that it was difficult to judge if elongated face was cause or effect of increased nasal resistance.

Vig $^{25}$ (1998) \& Fields ${ }^{26}$ et al. (1991), however, suggested that causal association between nasal obstruction and facial growth in children seem to be of multi-factorial nature. Klein ${ }^{27}$ (1986) \& Vickers ${ }^{28}$ (1998) did not report any conclusive evidence of the impact of mouth breathing on the development of more elongated faces which are resulted from different neuromuscular adaptations linked to a predetermined genetic pattern. Shintani ${ }^{29}$ at al. (1996) suggested that abnormal facial morphology found in mouth breathing patients could be influenced by genetic and environmental factors (upper airways obstruction).

Trotman $^{30}$ at al. (1997) also observed posterior rotation of the mandible and reduced posterior lower facial height in children with pharyngeal and palate tonsil hypertrophy aged 3 to 13 years. This observation, however was obtained from a selected sample with diagnosis performed through pharyngeal and palate tonsil observation in lateral cephalometric radiographs and clinical records, therefore not a very accurate diagnosis of nasal obstruction.

In a study in which differences in both genders were assessed, Kawashima $^{31}$ (2002) found that pre-school boys with respiratory disorder during sleep presented higher anterior lower facial height than girls. In spite of that, $\mathrm{Vig}^{25}$ (1998) recorded a significantly higher percentage of nose breathing among girls than boys.

Conversely, evidences that Gonion angle (ArGo.GoMe) present statistically different values in mouth breathing children and nasal breathing children evaluated in this study were not found. This result was not reported by Ahlqvist-Rastad ${ }^{32}$ et al. (1988), once they found increased Gonion angles in mouth breathing children if compared against nasal breathing children. Discrepant findings could be due to samples used in both studies, especially in regards of the children's age in the group evaluated by AhlqvistRastad $^{32}$ et al. (1988), which had a very large age range from 1 to 14 years. Additionally, the study was performed with higher sample size (122 pediatric patients) regardless of the fact the group was heterogeneous in terms of age. Such fact may mask results, since it involves different age groups and phases of facial growth. One of the aspects to be considered is the fact that fourteen-year old individuals have already definitive facial dimensions achieved, whereas ten-year old individuals have not undergone puberty growth, and may still present considerable modifications in facial morphology. This study evaluated children aged 6 to 10 years with increased frequency of individuals aged 7 to 9 years, which did not have their full potential growth yet. According to Defabjanis ${ }^{33}$ (2003), maxilla and mandible present considerable growth in size at the age of 12 in such way that $90 \%$ of deformities occur up to this time period. 
Unanimous consensus was not found, however, data seem to suggest a correlation between respiratory impairment and dentofacial deformity. Regardless of the lack of total understanding, maintenance and establishment of nose breathing is a key factor for proper dentofacial growth and development.

\section{CONCLUSION}

Mouth breathing children tend to present increased mandibular inclination, vertical growth pattern with changes in normal facial proportions, characterized by increased anterior lower facial height and decreased posterior facial height in mouth breathing children, therefore evidencing the influence of respiratory function in craniofacial development.

\section{REFERENCES}

1. Moss ML. The primary role of functional matrices in facial growth. Am J Orthod 1969; 55(6): 566-77.

2. Prates NS, Magnani MBBA, Vladrighi, HC. Respiração bucal e problemas ortodônticos: relação causa-efeito. Rev Paul Odontol 1997; 19(4): 14-8.

3. Linder-Aronson S. Adenoids: their effect on the mode of breathing and nasal airflow and their relationship to characteristics of the facial skeleton and the dentition. Acta Oto-laryng Suppl 1970; 265: 5-132.

4. Principato JJ. Upper airway obstruction and craniofacial morphology. Otolayngol. Head Neck Surg 1991; 104(6): 881-90.

5. Proffit WR. Contemporary Orthodontics. 2nd ed. Saint Louis: MosbyYear Book; 1993.

6. Weckx LLM, Weckx LY. Respirador bucal: causas e conseqüências. Rev Bras de Medicina 1995; 52(8): 863-74.

7. Subtelny JD. Effects of diseases of tonsils and adenoids on dentofacial morphology. Am Otol Rhinol Laryngol 1975; 84(2): part 2, p.504, Mar./Apr. 1975. Supplement 19.

8. Shendal SA, Eisenfeld J, Bell WH, Epker NB, Mishelevich DJ. The long face syndrome: Vertical maxillary excess. Am J Orthod 1976; 70(4): 398-408.

9. Hulcrantz E, Larson M, Hellquist R, Ahlqvist-Rastad J, Svanholm H, Jakobson OP. The influence of tonsilar obstruction and tonsillectomy on facial growth and dental arch morphology. Int J Pediatr Otorhinolaryngol 1991; 22(2): 125-34.

10. Warren DW. Effect of airway obstruction upon facial growth. Otolaryngol Clin North America 1990; 23(4): 699-712.

11. Tourné LPM. Growth of the pharynx and its physiologic implications. Am J Dentofacial Orthop 1991; 99(2): 129-39.

12. Tourné LPM, Scheweiger J. Imediate postural responses to total nasal obstruction. Am J Dentofacial Orthop 1996; 110(6): 606-11.

13. Brodsky L, Koch RJ. Anatomic correlates of normal and diseased adenoids in children. Laryngoscope 1992; 102: 1268-74.
14. Cohen D, Konak S. The evaluation of radiographs of the nasopharynx. Clin Otolaryngol 1985; 10: 73-8.

15. Aragão W. Respirador Bucal. Bol. Inform. Ass Bras Ortop Max 1985; 2(1): 3-4

16. Hinton VA, Warren DF, Hairfield WM. Upper airway pressures during breathing: a comparison of normal and nasally incompetent subjects with modeling studies. Am J Orthod 1986; 89(6): 492-8.

17. Lyle K. Airway compromise and dentofacial abnormalities. JGO. 2000; 11: 9-18.

18. Kawashima T, Peltomaki T, Sakata H, Mori K, Happonen RP, Ronning O. Craniofacial morphology in preschool children with sleep-related breathing disorder and hypertrophy of tonsils. Acta Paediatr 2002; 91: 71-7.

19. Kerr WJS, Mcwilliam JS, Linder-Aronson S. Mandibular form and position related to changed mode of breathing - a five-year longitudinal study. The Angle Orthod 1989; 59(2): 91-6.

20. Yang K, Zeng X, Yu M. A study on the difference of craniofacial morphology between oral and nasal breathing children. Zhonghua Kou Qiang Yi Xue Za Zhi. 2002; 37(5): 385-7.

21. Horn AJ. Facial height index. Am J Orthod Dentofac Orthop 1992; 102: $180-6$.

22. Tourné LPM. The long face syndrome and impairment of the nasopharyngeal airway. The Angle Orthod 1990; 60(3): 167-76.

23. Ung N, Koenig J, Shapiro PA, Shapiro G, Trsk G. A quantitative assessment of respiratory patterns and their effects on dentofacial development. Am J Orthod Dentofac Orthop 1990; 98: 523-32.

24. Smith RM, Gonzalez C. The relationship between nasal obstruction and craniofacial growth. Ped Clinic of North America 1989; 36(6): 1423-34.

25. Vig KWL. Nasal obstruction and facial growth: The strength of evidence for clinical assumptions. Am J Orthod Dentofac Orthop 1998; 113: 603-11.

26. Fields HW, Warren DW, Black K, Phillips CL. Relationship between vertical dentofacial morphology and respiration in adolescents. Am J Orthod Dentofac Orthop 1991; 99: 147-54.

27. Klein JC. Nasal respiratory function and craniofacial growth. Arch Otolaryngol. Head Neck Surg 1986; 112: 843-9.

28. Vickers DP. Respiratory obstruction and its role in long face syndrome. Northwest Dent 1998: 19-22.

29. Shintani T, Asakura K, Kataura A. Adenotonsillar hypertrophy and skeletal morphology of children with obstructive sleep apnea syndrome. Acta Otolaryngol Suppl 1996; 523: 222-4.

30. Trotman CA, Mcnamara JAJr, Dibbets JMH, Weele LTVD. Association of lip posture and the dimensions of the tonsils and sagittal airway with facial morphology. The Angle Orthod 1997; 67(6): 425-32.

31. Kawashima S. Sex-dependent differences in the craniofacial morphology of children with a sleep-related breathing disorder. Oral Surg. Oral Med. Oral Pathol. Oral Radiol Endod 2002; 94: 167-74.

32. Ahlqvist-Rastad J, Hultcrantz E, Svanholm H. Children with tonsillar obstruction: indications for and efficacy of tonsillectomy. Acta Paediatr Scand 1988, 77(6): 831-5.

33. Defabjanis P. Impact of nasal airway obstruction on dentofacial development and sep disturbances in children: preliminary notes. J Clin Ped Dent 2003; 27(2): 95-100. 